protocols are now being adapted to commercially available sequenators.

Protein phosphorylation is one of the most important post-translational modifications that escapes high-sensitivity detection in current sequencing methods. Simple modifications in hardware and chemistry have led to the efficient extraction of anilinothiozolinylphosphotyrosine in the solid-phase sequencing mode. Phosphorylated serine and threonine residues have been determined by the simultaneous detection of extracted, betaeliminated phosphate and the corresponding phenylthiohydantoins in the respective degradation cycles ${ }^{4,12}$.

Using the same prototype instrument, sequencing with phenylisothiocyanate, cycle times as short as 16 minutes were achieved $^{4.11}$. This represents the shortest cycle time reported to date for any mode of chemical sequence analysis. Probably the most significant consequence of the chemical flexibility inherent in the solidphase approach is the possibility of using a wide variety of sequencing reagents yielding amino acid derivatives with enhanced detectability. We have used the chromophoric reagent 4- $N, N$-dimethylaminoazobenzene- 4 '-phenylisothiocyanate, a well characterized protein sequencing reagent, as a model compound for this class of reagents ${ }^{4,13}$. Although sensitivity at the subpicomole level was easily achieved, increased sensitivity by two orders of magnitude will require the synthesis of new sequencing reagents rationally designed for optimal detectability in improved analytical systems consisting of massspectrometers or detectors for laserinduced fluorescence, photothermal refraction, or chemiluminescence connected on-line to capillary electrophoresis or microbore chromatography systems ${ }^{14-16}$.

The development of simple, fast, sensitive and highly efficicnt methods for the preparation of polypeptides for highsensitivity solid-phase sequence analysis and the introduction of a commercially available solid-phase sequenator have revived interest in this approach. In the future, the synthesis of sequencing reagents with enhanced detectablity, and the on-line connection of highly sensitive analytical systems, will undoubtedly produce further increases in sequencing sensitivity.

Ruedi Aebersold is Assistant Professor, Biochemistry, at the Biomedical Research Centre, 2222 Health Sciences Mall, University of British Columbia, Vancouver, British Columbia, Canada V6T 1W5. For more information, fill in reader service number 100. Ruedi Aebersold would like to thank Dr D. Teplow for his critical review of the manuscript.

1. Hewick, R.M., Hunkapiller, M.W., Hood, L.E. \& Dreyer, W.J. J. biol. Chem. 256, 7990-7997 (1981).

2. Laursen, R.A. Eur. J. Biochem. 20, 89-102 (1971).

3. Aebersold, R., Pipes, G., Nika, H., Hood, L.E. \& Kent, S.B.H. Biochemistry 27, 6860-6867 (1988).
Bio/Tech roundup

Products featured at next week's Bio/Technology Winter Symposium in Miami, Florida, include a high-throughput DNA sequencer and an antibody purification system.

PHARMACIA LKB Biotechnology announces the new Automated Laser Fluorescent (A.L.F.) DNA sequencer, which is designed to sequence and evaluate up to eight kilobases per day (Reader Service No. 101). The A.L.F. DNA Sequencer offers easy sample preparation and straightforward reaction chemistry, says Pharmacia. Using just one fluorescentlylabelled primer, samples are prepared by classical Sanger methods with the sequencing kit. In less than one hour, samples can be loaded onto the gel, without the need for extra quantitation or precipitation steps. Custom fluorescent primers can be prepared using the primer synthesis kit. Sample bands are detected with a fixed laser beam that penetrates the entire width of the gel. Dedicated software, run on a multitasking computer system, offers complete system control, rapid interpretation of raw and processed data, post-run evaluation capabilities, and access to stored data while sequencing is in progress. See the A.L.F. DNA Sequencer in booths $31 / 32$.

The System 100 biocompatible affinity protein purification unit provides a means of collecting purified antibody or antigen within 20 minutes, says Genex (Reader Service No. 102). Housed in a compact benchtop unit is a single-piston pump with rapid refill facility, a UV fixed-wavelength detector optimized for proteins at $280 \mathrm{~nm}$, preprepared buffers in ready-to-use bottles, and GammaBind $G$ silica or agarose columns - although other column matricies can be used. The system offers four modes of operation. In pro-

4. Aebersold, R. et at. in Methods in Protein Sequence Analysis (ed. Wittmann-Liebold, B.) (Springer, Berlin, 1989).

5. Pappin, D.J.C., Coull, J.M. \& Koester, H. in Current Research in Protein Chemistry, 191-202 (ed. Villafranca, J.) (Academic, San Diego, in the press).

6. Coull, J.M., Pappin, D.J.C., Mark, J., Aebersold, R. \& Koester, H. Analyt. Biochem. Submitted.

7. Third Symp. Protein Soc., Seattle, 29 July-2 August 1989. Manual prepared for MilliGen/Biosearch Protein Sequencing Forum.

8. Solid-phase Methods in Protein Sequence Analysis (ed Laursen, R.A.) (Pierce Chem. Co., Rockford, II, 1975).

9. Wachter, E., Machleidt, W., Hofner, H. \& Otto, J. FEBS Lett. 35, 97-102 (1973)

10. Aebersold, R., Teplow, D., Hood, L.E. \& Kent, S.B.H. biol. Chem. 261, 4229-4238 (1986).

11. Nika, H., Aebersold, R., Hood, L.E. \& Kent, S.B.H. In preparation.

12. Wettenhail, R.E.M., Aebersold, R., Hood, L.E. \& Kent, S.B.H. Meth. Enzym. Submitted.

13. Chang, J.Y. \& Creaser, E.H. Biochem. J. 157, 77-82 (1976)

14. Yu, M. \& Dovichi, N.J. Analyt. Chem. 61, 37-40 (1989) 15. Jin, S.W., Chen, G.X., Palacz, Z. \& Wittmann-Liebold, B. FEBS Lett. 198, 150-158 (1986).

16. Cheng, Y.F. \& Dovichi, N.J. Science 242, 562-564 (1988). gram mode, the user can optimize methods by creating, storing and editing up to nine user-defined protocols. According to Genex, the System 100 is scalable and can be used to purify over one gram per day with 90-95 per cent purity. Stated applications include the purification of antibodies from serum and ascites, purification of antigens with immunoaffinity columns, and removal of $\mathrm{IgG}$ from serum for IgM or IgE detection. See Genex in booth 40 .

Immunoselect is the new monoclonal antibody-based isotyping system for the identification of mouse immunoglobulins, without, says Life Technologies, cross reactivity (Reader Service No. 103). Based

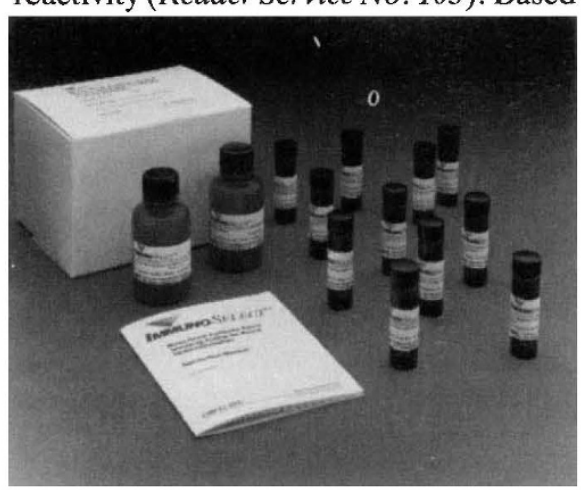

Immunoselect isotyping system.

on an antibody-capture ELISA, Immunoselect utilizes monoclonal rat anti-mouse Ig antibodies against all the major classes and subclasses of mouse immunoglobulins. The isotyping system comes complete with all the necessary Gibco/BRL-brand reagents to isotype $50-100$ clones and will be on display in booths $21 / 22$.

\section{Hybridization of Southern/Northern} Blots with DNA/RNA probes

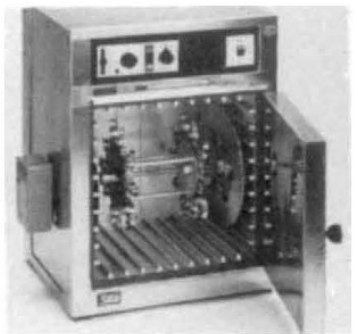

Our accurately temperature-controlled rotisserie 2.4-3 ml hybridization solution. Lower background. Higher intensity of bands. Multiple hybridizations possible. Uniform distribution of hybridizatio
solution.

BACHOFER GmbH P.O. Box 7089 D-7410 Reutlingen W-Germany oven gives important advantages as against bag: 